\title{
Caso de parada cardiorrespiratoria intrahemodiálisis en un centro periférico
}

\author{
Ma José Marqués Racionero, Macarena Peña Ortega, Virginia A. Marín Fábrega, Mª Luisa Molina Conde
}

Club de Hemodiálisis Nefrolinares. Linares. Jaén

\section{Introducción:}

La incidencia de parada cardiorrespiratoria (PCR) en hemodiálisis (HD) es baja y aunque en los últimos 10 años ha bajado más, alrededor de 7/100.000 en 2001 a 4,5/100.000 en 2010, aún así la mortalidad en pacientes en tratamiento con HD es $10-20$ veces mayor que en la población general. Debido a esta baja incidencia el personal de enfermería no está habituado a actuar ante una situación de emergencia, pues hay estudios en los que se obtienen como resultados que el $50 \%$ de la enfermería no se considera capacitada para actuar en una PCR y el nivel de formación y conocimientos es bajo.

\section{Objetivos:}

- Presentar un caso de PCR durante la sesión de HD en un centro periférico.

- Analizar las particularidades que rodean a la PCR en pacientes en programa de HD.

\section{Material y método:}

- Caso clínico de un paciente en PCR intraHD.

- Revisión bibliográfica.

Palabras clave: Parada cardiorrespiratoria, hemodiálisis, periférico, reanimación.

\section{Desarrollo:}

Según la bibliografía revisada la PCR es una relativamente infrecuente pero devastadora complicación de la HD. A los factores de riesgo clásicos de la PCR hay que añadir, en los pacientes incluidos en programa de HD, otros como el transcurso de la sesión de los lunes, haber sufrido un ingreso hospitalario en el último mes o portar un catéter, percutáneo o tunelizado, como acceso vascular. Si un paciente entra en estado de PCR el riesgo de muerte es inminente, por lo que la actuación inmediata es fundamental. El patrón que se produce con más frecuencia en la PCR es la Fibrilación Ventricular (FV) que degenera en Asistolia (A) si no se desfibrila de manera precoz. Presentamos el caso de un paciente de 76 años que tiene como factores de riesgo de PCR asociados a la HD ingreso en el último mes y portador de catéter como acceso vascular. Queda inconsciente en los últimos minutos de la sesión de HD. Tras la valoración del mismo durante los primeros 10 segundos por el personal de enfermería y el nefrólogo se diagnostica PCR. Se inicia la Cadena de Supervivencia con el aviso al EE y diagnóstico de A y Reanimación cardiopulmonar (RCP) básico y medicación hasta la llegada del equipo de emergencias (EE). Anexo 1. Protocolo de actuación del personal de nuestra unidad durante el caso. Anexo 2. Cadena de supervivencia. Anexo 3. Curva de Drinker.

\section{Conclusiones:}

Existen factores de riesgo de PCR propios de los pacientes en programa de HD que el personal sanitario que está en contacto con ellos debe conocer y valorar para ayudar en la prevención y la asistencia 
precoz de los casos. No sólo es necesaria la existencia en cada unidad de hemodiálisis de un desfibrilador sino que el personal sanitario del centro conozca su funcionamiento. Es fundamental el reciclaje del personal que está en contacto con los pacientes en programa de HD para favorecer actuaciones más rápidas, eficaces y seguras.

\section{Referencias Bibliográficas}

1. Álvarez González M. Parada cardiaca y muerte súbita en unidad de diálisis. Revista electrónica de Medicina Intensiva [Revista en línea] 2001 [citado 12 abril 2013]; 1(9) Disponible en: http://remi.uninet.edu/2001/09/REMI021l.htm.
2. Modifiable risk factors associated withsudden cardiac arrest within hemodialysos clinics. Kidney int 2011 Jan 79(2): 218-27 doi: 10.1038/ ki 2010.315 Epub 2010 Sep. 1.[citado 12 abril 2013]; Disponible en: http://www.ncbi.nIm.nih.gov/ pubmed/20811332.

3. Brazález M, García P, Turrión V. Autoconocimiento y habilidades en reanimación cardiopulmonar del personal enfermero de nefrología. Revista Seden [en línea] 2012 [citado el 14 abril 2013] FRIAT Centro los Pinos. Valladolid; 15 Supl 1.Disponible en: http://www. revistaseden.org/imprimir.asp?idArticulo=3029.

4. Perales N, López J, Ruano M.Manual de soporte vital avanzado.4a.ed. Elsevier Masson.2007. 